\title{
Illness beliefs about hypertension among non-patients and healthy relatives of patients
}

\author{
Antonio Del Castillo ${ }^{1}$, Débora Godoy-Izquierdo ${ }^{1,2^{\star}}, M^{\text {a }}{ }^{-}$Luisa Vázquez ${ }^{1}$, Juan F. Godoy ${ }^{1,2}$ \\ ${ }^{1}$ Grupo de Investigación Psicología de la Salud y Medicina Conductual (CTS-267), Universidad de Granada, Campus de Cartuja, \\ Granada, Spain; *Corresponding Author: deborag@ugr.es \\ ${ }^{2}$ Departamento de Personalidad, Evaluación y Tratamiento Psicológico, Facultad de Psicología, Universidad de Granada, Campus de \\ Cartuja, Granada, Spain
}

Received 5 March 2013; revised 3 April 2013; accepted 13 April 2013

Copyright (C) 2013 Antonio Del Castillo et al. This is an open access article distributed under the Creative Commons Attribution License, which permits unrestricted use, distribution, and reproduction in any medium, provided the original work is properly cited.

\section{ABSTRACT}

Objectives: Personal beliefs about illnesses have received increasing interest because these cognitions help to explain and predict preventive and therapeutic coping efforts, adjustment to a disease and health outcomes. We sought to explore and compare non-specialised illness representations of hypertension among adults never suffering from hypertension who had and had not lived with hypertensive patients. Design: Hypertension representations were explored in a community-based, convenient sample of normotensive Spanish adults of both genders from different educational backgrounds and with different family experience with this illness. Method: An adapted IIIness Perception Questionnaire-R was used to assess such perceptions among healthy people in nine dimensions: Identity, Timeline, Consequences, Personal Control, Treatment Control, Illness Coherence, Evolution, Emotional Representations and Causes. Results: The participants' beliefs mixed accurate and folk knowledge, while gender, age and education level had little impact, family experience (having or not having a relative with hypertension) strongly determined the content of hypertension representations. Participants with family experience held significantly stronger beliefs of controllability of the disease, both by patients and treatments, considered the disease as less stable and reported a lower emotional impact when thinking on suffering from hypertension. Family experience was the only significant predictor of illness cognitions. Conclusions: This study allowed us to know the perceptions of hypertension among non-patients and healthy relatives of patients. Our findings are useful in designing interventions aimed at hypertension prevention, particularly considering family experience with the disease.

Keywords: Illness Representations; IPQ-R; Hypertension; Non-Patients; Prevention

\section{INTRODUCTION}

Hypertension is a public health problem in both economically developing and developed nations. Nearly one third of the adult worldwide population has hypertension [1-3]. In Spain, hypertension prevalence in the adult population is currently around $35 \%$, affecting around 10 million people [4]. Although hypertension is not a severe disease by itself, it is considered a "silent killer" because high blood pressure is an important risk factor for other more serious disorders such as cardiovascular, kidney, eye or pulmonary diseases. Thus, hypertension is a major source of morbidity and mortality.

According to the Self-Regulation Model of Common Sense Illness Representations (SRM) [5-13], people are active decision-makers and problem solvers and play an agentic role in self-regulation. Both healthy and ill people construct non-specialized models about illnesses which comprise a series of cognitive and emotional representations to create an integrated, comprehensive and meaningful picture of a health-threatening condition. Illness representations derive from several informational sources, including: 1) an individual's knowledge and direct experiences; 2) sociocultural knowledge; and 3) information and experiences from significant others (e.g., relatives, physicians) [6,7].

Sociodemographic variables such as gender, age and educational level are not usually significant correlates of illness beliefs in the case of physical diseases [14-16], 
although a number of exceptions have been reported [17-19]. However, having suffered from the disease or having an ill relative consistently emerges as a relevant contributor to illness representations for physical illnesses [14-16,20-28].

Individuals use these representations to evaluate the risks for health and well-being, and then direct diverse behavioural and emotional efforts to face the perceived risks and to protect health. Individuals who are already ill use these representations to manage their condition, to control its consequences in their lives and to recover their health, well-being and quality of life. Therefore, as for the SRM illness representations directly influence the illness-related emotion- and problem-focused coping actions and indirectly, by a mediation path of coping, also influence the consequences of illnesses and the adjustment to the disease. There is substantial evidence from populations with different physical and mental illnesses supporting the relationship between illness perceptions and specific coping behaviours (such as adherence to medical recommendations) and between illness beliefs and a wide range of consequences (such as quality of life) (see [29-32] for a review).

Although hypertension is a frequent disease, non-specialised illness beliefs about it have been examined in only a few studies. Research conducted with hypertensive patients $[23,33-41]$ has shown that their representations of the disease include biomedical knowledge mixed with folk information, and that those representations impact on their illness-related behaviours, such as adherence to treatments. Some of these studies have also examined the impact of sociodemographic conditions on hypertension beliefs. Ross et al. (2004) found that men, compared to women, considered that hypertension has a broader impact on the patient's life, but also held stronger beliefs of personal and treatment control on the disease. Older participants, compared to younger participants, held weaker beliefs on consequences, personal control and emotional impact, but stronger perceptions on treatment control. Wilson et al. (2002) also found that younger participants' underestimated mortality associated with hypertension. Research on hypertension beliefs among healthy individuals is very sparse and the findings are inconclusive. Wilson et al. (2002) assessed beliefs about hypertension in an African-American sample including hypertensive patients and healthy people. The disease was perceived by most of the participants, with no discrimination between healthy and hypertensive participants, as symptomatic, caused mainly by stress, heredity and eating habits and treatable with vitamins, home remedies, medication and lifestyle changes. Meyer et al. (1985) sampled 230 individuals, 50 of whom were nonhypertensive, and found that both normotensive and hypertensive participants believed that symptoms were as- sociated with elevations in blood pressure, and consequently could be used to monitor blood pressure elevations, that the disease has a limited duration and that it is caused by a variety of environmental and psychosocial conditions, such as work or family problems, stress and diet.

To our knowledge, only one study has been conducted with Spanish population. Godoy-Izquierdo et al. (2007) investigated illness representations for several diseases (cancer, hypertension, influenza, depression and schizophrenia) in a sample of university students who had or had not had any of those diseases and who did or did not live with a patient suffering from any of them. They utilized a less-used survey for assessing illness beliefs. Approximately $2.5 \%$ of the participants suffered or had suffered from hypertension, and $43.5 \%$ were living or had previously lived with a hypertensive patient. Most of the participants believed that hypertension had no bodily symptoms, it had a notable impact on patients' life and it was long-lasting but amenable to cure. A high percentage of participants thought that hypertension was linked to psychological factors, such as stress and emotional activation or lack of rest. These findings are consistent in many respects with those from studies of hypertensive patients $[34,35,37,39,41]$, but they differ particularly on the identity dimension, as patients tended to believe that high blood pressure manifests through bodily symptoms.

Godoy-Izquierdo et al. (2007) also found for the diseases studied that the illness cognitions of participants who had either personal experience of the diseases or a diagnosed relative were significantly different from those of participants without such a direct or family experience. Compared to participants without a personal or family experience, patients and their relatives perceived the diseases as significantly less chronic and serious, more stable but also recurrent, with fewer or less severe conesquences for daily functioning and well-being, as more preventable and controllable, and as more amenable to a cure. These findings imply an essential influence of experience with a disease on lay representations of it.

The present study was conducted to address and compare the illness representations of hypertension among healthy, normotensive Spanish adults who differed in their family experiences with the disease. To our knowledge, no study has considered the impact of sociodemographic factors on the representations of hypertension specifically among healthy people, and we also addressed this issue. We used the most widely accepted SRM-derived tool for assessing illness representations: the revised version [42] of the Illness Perception Questionnaire [43]. Based on previous findings in the above-mentioned illness representations studies, we predicted that the participants' beliefs about hypertension would reflect both biomedical knowledge and folk information. We did not 
expect that gender, age or educational level would influence hypertension representations. However, we expected that the experience of living with a hypertensive patient would impact the representations of healthy participants.

\section{METHODS}

\subsection{Participants}

A total of 130 adults (50\% women) 18 to 66 years old $(M=39.97 ; S D=13.81)$ participated. Table 1 displays their most relevant characteristics. At the time of the study, none of the participants had ever suffered from hypertension, and $38.5 \%$ (50 participants) had lived or were currently living with any relative who had hypertension. This community-based, convenience sample was recruited at random from private households and community settings such as public transport stations, workplaces, parks, healthcare service delivery locations, academic centres and shopping centres. In $17.7 \%$ of cases, participants reported suffering from a physical or mental disease at the time of the study. More frequently reported diseases were depression (30.4\%), anxiety (26.1\%) and diabetes $(17.4 \%)$. The other reported illnesses affected only one or two individuals each. No participant reported any severe illness.

\subsection{Measures}

The participants completed a Spanish-modified version of the Revised Illness Perception Questionnaire
(IPQ-R) by Moss-Morris et al. (2002) adapted to assess illness perceptions among healthy people [21]. The IPQ$\mathrm{R}$ evaluates nine dimensions from Leventhal and colleagues' SRM model and research findings [42]: Identity (symptoms associated with the illness and label); Timeline (duration and chronicity); Consequences (effects of the illness on an individual's lifestyle, health and wellbeing); Personal Control (personal influence on preventing and managing the disease); Treatment Control (availability and efficacy of treatments to manage or cure the disease and its symptoms); Illness Coherence (personal understanding of the disease); Evolution (course and temporal changeability or fluctuation of the illness and symptoms); Emotional Representations (emotional impact of the disease) and Aetiology or Causes (psychological, behavioural, biological, chance and external causes of the disease).

For all of the dimensions except identity and causes, a series of statements (e.g., "My illness does not worry me") are included for which the person must express his or her level of agreement on a Likert-type scale with five alternatives (from "Strongly disagree" to "Strongly agree"). For all these subscales, partial scores were defined as the mean of the scores for the items on each subscale (considering direct and inverse items, see Table 2), with higher scores indicating stronger beliefs about the disease chronicity, cyclical course, impact and outcomes, personal influence, cure possibilities, perceived understanding and emotional reactions to the disease. For the

Table 1. Socio-demographic data.

\begin{tabular}{|c|c|c|}
\hline & & $\%$ \\
\hline Age ranges & $\begin{array}{l}18-25 \\
26-35 \\
36-45 \\
46-55 \\
56-66\end{array}$ & $\begin{array}{l}20.8 \\
22.3 \\
17.7 \\
21.5 \\
17.7\end{array}$ \\
\hline $\begin{array}{l}\text { Educational level } \\
\text { (highest completed level) }\end{array}$ & $\begin{array}{c}\text { No formal education } \\
\text { Primary school } \\
\text { Secondary school } \\
\text { Vocational training } \\
\text { and other formal education } \\
\text { University }\end{array}$ & $\begin{array}{c}7.7 \\
21.5 \\
27.7 \\
9.2 \\
33.8\end{array}$ \\
\hline Work status & $\begin{array}{c}\text { Student } \\
\text { Employed } \\
\text { Student \& Employed } \\
\text { Housework } \\
\text { Unemployed }\end{array}$ & $\begin{array}{c}13.1 \\
59.2 \\
5.4 \\
14.6 \\
7.7\end{array}$ \\
\hline Marital status & $\begin{array}{c}\text { Single } \\
\text { Short-term relationship }(<3 \text { years }) \\
\text { Long-term relationship }(>3 \text { years }) \\
\text { Separated/Divorced } \\
\text { Widow }\end{array}$ & $\begin{array}{r}19.2 \\
23.8 \\
47.7 \\
6.9 \\
2.3\end{array}$ \\
\hline $\begin{array}{l}\text { Physical or mental disease } \\
\text { at the time of the study }\end{array}$ & $\begin{array}{l}\text { Yes } \\
\text { No }\end{array}$ & $\begin{array}{l}17.7 \\
82.3\end{array}$ \\
\hline
\end{tabular}


Table 2. Percentages of agreement responses and descriptive results for each subscale.

\begin{tabular}{|c|c|c|}
\hline & Dimensions & $\%$ \\
\hline $\begin{array}{c}\text { Identity }\left(0-15^{\mathrm{a}}\right) \\
\text { (perceived symptoms of } \\
\text { hypertension) } \\
M=5.38, S D=2.51 ; \mathrm{R}=0-13\end{array}$ & $\begin{array}{l}\text { Fatigue, tiredness } \\
\text { Tachycardia }^{\mathrm{b}} \\
\text { Dizziness, vertigo }^{\mathrm{b}} \\
\text { Pain anywhere }^{\mathrm{b}} \\
\text { Emotional distress, sadness or anxiety }^{\mathrm{b}} \\
\text { Weakness, loss of strength }^{\mathrm{b}} \\
\text { Breathlessness, respiratory problems }^{\mathrm{b}} \\
\text { Sleep difficulties } \\
\text { Nausea } \\
\text { Mobility difficulties } \\
\text { Stiff joints } \\
\text { Stomach-intestine problems } \\
\text { Fever }^{\mathrm{b}} \\
\text { Weight loss }^{\mathrm{b}} \\
\text { Delirium and hallucinations }^{\mathrm{b}}\end{array}$ & $\begin{array}{c}76.2^{\mathrm{c}} \\
76.2 \\
74.6 \\
49.2 \\
43.1 \\
40 \\
39.2 \\
34.6 \\
23.1 \\
17.7 \\
16.2 \\
11.5 \\
10 \\
9.2 \\
7.7\end{array}$ \\
\hline $\begin{array}{l}\text { Timeline (acute/chronic) }(1-5) \\
\quad(\text { This illness...) } \\
M=3.92, S D=0.65 ; \mathrm{R}=2.17-5\end{array}$ & $\begin{array}{l}\text { 3. Will last for a long-time } \\
\text { 2. Is likely to be permanent rather than temporary } \\
\text { 5. Is expected to be for life } \\
\text { 6. Will improve in time } \text { (Item } 18 \text { in IPQ-R) }^{\text {4. Will pass quickly }} \\
\text { 1. Will last a short time } \\
\text { e }\end{array}$ & $\begin{array}{c}80^{\mathrm{d}} \\
69.2 \\
63 \\
17.7 \\
7.7 \\
2.3\end{array}$ \\
\hline $\begin{array}{c}\text { Consequences }(1-5) \\
\quad(\text { This illness...) } \\
M=2.87, S D=0.57 ; \mathrm{R}=1.33-5\end{array}$ & $\begin{array}{l}\text { 7. Is a serious condition } \\
\text { 8. Has major consequences on patient's life } \\
\text { 12. Causes difficulties for the people close to patients } \\
\text { 9. Does not have much effect on patient's life } \\
\text { 11. Has serious financial consequences } \\
\text { 10. Strongly affects the way others see patients }\end{array}$ & $\begin{array}{l}59.3^{\mathrm{d}} \\
49.2 \\
14.6 \\
12.3 \\
12.3 \\
8.5\end{array}$ \\
\hline $\begin{array}{c}\text { Personal control }(1-5) \\
M=4.18, S D=0.58 ; \mathrm{R}=2-5\end{array}$ & $\begin{array}{l}\text { 17. Patients have the power to influence their illness } \\
\text { 14. What patients do can determine whether their disease gets better or worse } \\
\text { 13. There is a lot which patients can do to control their symptoms } \\
\text { 15. The course of the disease depends on the patient } \\
\text { 18. A patient's actions will have no effect on the outcomes of her/his illness } \\
\text { 16. Nothing the patient does will affect his/her illness }\end{array}$ & $\begin{array}{l}94.6^{\mathrm{d}} \\
88.4 \\
85.4 \\
73 \\
8.4 \\
5.3\end{array}$ \\
\hline $\begin{array}{c}\text { Treatment control }(1-5) \\
M=3.91, S D=0.45 ; \mathrm{R}=2.71-5\end{array}$ & $\begin{array}{l}\text { 22. The treatment can control the disease and its negative effects } \\
\text { 21. The illness can be prevented } \\
\text { 20. The treatment effectively relieves the symptoms but does not cure the disease (new) } \\
\text { 25. Some treatment or intervention exists which is effective in curing this disease (medication, } \\
\text { therapy, surgery, rehabilitation...) (Item } 20 \text { in IPQ-R) } \\
\text { 23. There is nothing which can help the patient's condition }{ }^{\mathrm{e}} \\
\text { 19. There is very little that can be done to improve when ill } \\
\text { 24. This illness goes away or is cured by its own }{ }^{\mathrm{e}} \text { (new) }\end{array}$ & $\begin{array}{l}85.4^{\mathrm{d}} \\
76.2 \\
63 \\
38.4 \\
10 \\
3.8 \\
2.3\end{array}$ \\
\hline $\begin{array}{c}\text { Illness coherence }(1-5) \\
M=3.41, S D=0.89 ; \mathrm{R}=1.40-6\end{array}$ & $\begin{array}{l}\text { 30. I have a clear picture or understanding of the disease } \\
\text { 26. The symptoms of this disease are puzzling to } \mathrm{me}^{\mathrm{e}} \\
\text { 27. The disease is a mystery to me } \mathrm{e}^{\mathrm{e}} \\
\text { 28. I don't understand this illness } \\
\text { 29. The disease doesn't make any sense to } \mathrm{me}^{\mathrm{e}}\end{array}$ & $\begin{array}{l}51.6^{\mathrm{d}} \\
26.9 \\
23.1 \\
19.2 \\
7\end{array}$ \\
\hline $\begin{array}{l}\text { Evolution (timeline-cyclical) }(1-5) \\
\qquad M=2.83, S D=0.92 ; \mathrm{R}=1-5\end{array}$ & $\begin{array}{l}\text { 34. The patient goes through cycles in which the disease gets better and worse } \\
\text { 33. The disease is very unpredictable } \\
\text { 32. The symptoms come and go in cycles } \\
\text { 31. The symptoms of this disease change a great deal from day to day }\end{array}$ & $\begin{array}{c}34.7 \\
33 \\
29.2 \\
23.8\end{array}$ \\
\hline $\begin{array}{l}\text { Emotional representations }(1-5) \\
M=2.57, S D=0.79 ; \mathrm{R}=1-5\end{array}$ & $\begin{array}{l}\text { 38. I am not worried about this disease or suffering from it } \\
\text { 35. I get depressed when I think I have or may have this disease } \\
\text { 36. When I think on this disease I get upset } \\
\text { 40. Thinking on having this disease makes me feel afraid } \\
\text { 39. I feel anxious about the idea of having this disease } \\
\text { 37. To think on having this illness makes me feel angry }\end{array}$ & $\begin{array}{l}21.5^{\mathrm{d}} \\
15.3 \\
13.8 \\
12.3 \\
11.5 \\
9.2\end{array}$ \\
\hline
\end{tabular}




\begin{tabular}{|c|c|c|}
\hline & Diet, eating habits & $86.9^{\mathrm{d}}$ \\
\hline & Stress or worry & 84.6 \\
\hline & Smoking & 83.9 \\
\hline & Ageing & 81.6 \\
\hline & Overwork & 76.1 \\
\hline & Hereditary, genetic $^{\mathrm{b}}$ & 73.1 \\
\hline & Alcohol consumption ${ }^{\mathrm{b}}$ & 66.1 \\
\hline & Poor medical care in one's life & 51.6 \\
\hline & Family problems or worries & 48.5 \\
\hline Causes & One's own behaviour and habits ${ }^{\mathrm{b}}$ & 44.7 \\
\hline & One's own emotions and moods & 43 \\
\hline & Accident or injury & 41.5 \\
\hline & One's own mental attitude and thinkings ${ }^{\mathrm{b}}$ & 24.7 \\
\hline & Chance,bad luck & 22.3 \\
\hline & Pollution, environmental contamination ${ }^{\mathrm{b}}$ & 21.5 \\
\hline & One's own personality & 19.3 \\
\hline & Other people ${ }^{\mathrm{b}}$ (new) & 9.2 \\
\hline & Immunity problems ${ }^{\mathrm{b}}$ & 7.7 \\
\hline & Germs or viruses & 6.2 \\
\hline
\end{tabular}

Footnotes: Range of possible responses: Identity subscale: $1=$ Yes, 0 = No; Remaining subscales: 1 = "Strongly disagree"-5 = "Strongly agree". ${ }^{a}$ Minimum and maximum possible score in the subscale in the revised questionnaire used in this study; 'Symptoms/causes added, completed or grouped in categories; ${ }^{\text {b Per- }}$

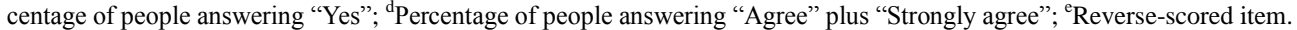

identity dimension, answers to whether each in a series of symptoms was perceived as characteristic of the disease were examined. The higher the score, the more symptomatic the disease was perceived to be. For the cause subscale, those factors scoring the highest in a series of possible causes are those the person considers to be the most relevant aetiological factors for the illness. A global score was calculated by summing the answers to all items excepting those from causes' subscale, with higher scores reflecting stronger illness representations.

Following previous suggestions [42,43], we modified the questionnaire to adapt it to non-patients and to make it more complete and better fitted to hypertension. Therefore, each reference to "my" illness was substituted by "the" illness or "hypertension". For the identity subscale, some new symptoms were added, while others were augmented with additional detail or re-categorised. Two new items (\#20 and \#24 in our version) were added to assess complementary beliefs about a cure for hypertension. Item 21 in our version was rewritten to assess beliefs about prevention of the disease. Items measuring the emotional representations dimension were also rewritten to assess emotional distress among healthy people. Items 22 and 25 were completed. Some causes were completed or added to the cause subscale (see all changes in Table 2).

The psychometric properties of the IPQ-R have been previously demonstrated among English-speaking and Spanish populations $[21,42,44]$, as well as in the context of hypertension [44]. The internal reliability of the IPQ-r version used was alpha $=0.77$ (the identity dimension was excluded from the analysis).

\subsection{Procedure}

After the study was approved by the institutional re- search ethics committee, participants were asked to take part voluntarily and to sign an informed consent form. They had been informed previously that the general objective of the study was to learn their beliefs about hypertension and not to gauge their level of knowledge. Specific instructions for completing the questionnaire were given. A survey requesting personal and sociodemographic data was also included and contained questions about whether participants had ever suffered from hypertension and whether they had ever lived with a relative who was diagnosed with hypertension.

A community-based convenience sample was constructed. Three housing buildings and several community settings per district were selected at random with a local telephone directory. A person in one of every three possible households and one of every three people in the public settings were asked to participate and followed the above-mentioned procedure when they accepted. Questionnaires from people suffering or having suffered from hypertension were not considered for analysis.

\subsection{Data Analyses}

We conducted preliminary analyses to detect errors in data, lost or absent data, or extreme and outlier values and to check parametric assumptions to make decisions on statistical tests. Given that the parametric assumptions were met in the majority of the variables (although Kolmogorov-Smirnov tests were usually significant, no significant Levene coefficients were found), we opted for parametric tests. Descriptive analyses, ANOVAs and $t$ tests for group comparisons and multiple linear regression analyses were conducted. In addition, Cohen's $d$ coefficient was calculated to estimate effect size (for equal or unequal sample sizes). 


\section{RESULTS}

\subsection{Non-Specialised Beliefs about Hypertension}

To establish the contents of illness models for hypertension in detail, descriptive data and the percentages of responses for each item were obtained (see Table 2 ).

\subsection{Influence of Gender, Age and Educational Level on Hypertension Representations}

Women showed stronger beliefs about identity, timeline and coherence for hypertension, while men had stronger beliefs about consequences, personal control, treatment control, evolution and emotional representation. We only found one significant difference: men believed that hypertension has more serious consequences for patients and their families than did women (see Table 3). The value of $d$ is moderate for this comparison and below 0.3 for the remaining ones.

We considered five age groupings for comparative purposes. In general, as age increased, stronger beliefs were found, with the exceptions of beliefs in the symptoms and coherence dimensions. Although no significant differences were found in the ANOVAs (see Table 4), we found marginally significant differences for two dimensions and the following significant differences in pair comparisons, accompanied by moderate to high effect sizes. Bonferroni's post hoc comparisons revealed that participants aged 26 - $35 \mathrm{yr}$ indicated significantly more symptoms than did participants aged $56-66 \mathrm{yr}(p=$ $0.028, d=0.93$ ), and Games-Howell's test showed that participants aged 18 - $25 \mathrm{yr}$ reported a significantly lower level of perceived personal control of the disease than did participants aged $56-66 \mathrm{yr}(p=0.047, d=0.78)$. In the dimension of emotional representations, although the comparison for participants aged 36 - $45 \mathrm{yr}$ and 46 - 55 yr was non-significant, the $d$ value was 0.67 , indicating a moderate effect size for this difference.

Participants' education level in the Spanish school system was also considered for comparison purposes. In general, as education level increased, stronger beliefs were found, with the exceptions of consequences and emotional representations dimensions, although university-educated participants usually showed a change in this pattern. ANOVAs showed significant differences for two dimensions and marginally significant differences for another one (see Table 5). Bonferroni's posthoc comparisons revealed significant differences for the dimension of timeline for participants with no formal education

Table 3. Comparisons according to gender.

\begin{tabular}{|c|c|c|c|c|c|c|c|}
\hline \multirow{2}{*}{ DIMENSIONS $^{\mathrm{a}}$} & \multicolumn{2}{|c|}{$\operatorname{MEN}(\mathrm{N}=65)$} & \multicolumn{2}{|c|}{ WOMEN $(\mathrm{N}=65)$} & \multirow{2}{*}{$t$} & \multirow{2}{*}{$p$} & \multirow{2}{*}{$d$} \\
\hline & $M$ & $S D$ & $M$ & $S D$ & & & \\
\hline Identity & 5.32 & 2.13 & 5.43 & 2.86 & $-0.243^{\dagger}$ & 0.808 & -0.04 \\
\hline Timeline & 3.9 & 0.68 & 3.93 & 0.62 & -0.292 & 0.770 & -0.05 \\
\hline Consequences & 2.98 & 0.66 & 2.75 & 0.44 & $2.414^{\dagger}$ & $0.017^{*}$ & 0.42 \\
\hline Personal control & 4.22 & 0.54 & 4.15 & 0.61 & 0.657 & 0.513 & 0.12 \\
\hline Treatment control & 3.95 & 0.43 & 3.87 & 0.47 & 0.945 & 0.346 & 0.18 \\
\hline Coherence & 3.33 & 0.93 & 3.5 & 0.86 & -1.101 & 0.273 & -0.19 \\
\hline Evolution & 2.89 & 0.94 & 2.78 & 0.9 & 0.692 & 0.490 & 0.12 \\
\hline Emotional representations & 2.66 & 0.7 & 2.48 & 0.88 & $1.292^{\dagger}$ & 0.199 & 0.23 \\
\hline
\end{tabular}

${ }^{\mathrm{a}}$ Aetiology dimension was not considered for comparison analyses; ${ }^{\dagger}$ Not considering equal variances; ${ }^{*} p<0.05$.

Table 4. Comparisons according to age.

\begin{tabular}{|c|c|c|c|c|c|c|c|c|c|c|c|c|}
\hline \multirow{2}{*}{ DIMENSION } & \multicolumn{2}{|c|}{$18-25(\mathrm{~N}=27)$} & \multicolumn{2}{|c|}{$26-35(\mathrm{~N}=29)$} & \multicolumn{2}{|c|}{$36-45(\mathrm{~N}=23)$} & \multicolumn{2}{|c|}{$46-55(N=28)$} & \multicolumn{2}{|c|}{$56-66(\mathrm{~N}=23)$} & \multirow{2}{*}{$F$} & \multirow{2}{*}{$p$} \\
\hline & $M$ & $S D$ & $M$ & $S D$ & $M$ & $S D$ & $M$ & $S D$ & $M$ & $S D$ & & \\
\hline Identity & 5.37 & 2.40 & 6.31 & 2.25 & 5.56 & 2.98 & 5.21 & 2.42 & 4.22 & 2.24 & 2.385 & 0.055 \\
\hline Timeline & 3.82 & 0.7 & 3.97 & 0.56 & 4.01 & 0.65 & 3.73 & 0.55 & 4.09 & 0.77 & 1.309 & 0.270 \\
\hline Consequences & 2.78 & 0.34 & 2.96 & 0.8 & 2.78 & 0.59 & 2.86 & 0.49 & 2.93 & 0.56 & 0.530 & 0.714 \\
\hline Personal control & 3.99 & 0.6 & 4.12 & 0.74 & 4.16 & 0.51 & 4.29 & 0.51 & 4.39 & 0.39 & 1.915 & 0.112 \\
\hline Treatment control & 3.78 & 0.35 & 3.98 & 0.46 & 3.97 & 0.46 & 3.9 & 0.54 & 3.93 & 0.42 & 0.818 & 0.516 \\
\hline Coherence & 3.44 & 0.71 & 3.52 & 0.98 & 3.61 & 0.87 & 3.17 & 0.93 & 3.33 & 0.95 & 0.956 & 0.434 \\
\hline Evolution & 2.57 & 0.84 & 2.97 & 0.88 & 3.07 & 1.07 & 2.77 & 0.83 & 2.8 & 0.97 & 1.124 & 0.348 \\
\hline Emotional representations & 2.49 & 0.99 & 2.44 & 0.84 & 2.4 & 0.75 & 2.84 & 0.57 & 2.69 & 0.73 & 1.469 & 0.216 \\
\hline
\end{tabular}


Table 5. Comparisons according to educational level.

\begin{tabular}{|c|c|c|c|c|c|c|c|c|c|c|c|c|}
\hline \multirow[t]{2}{*}{ DIMENSION } & \multicolumn{2}{|c|}{$\begin{array}{l}\text { No education } \\
\quad(\mathrm{N}=10)\end{array}$} & \multicolumn{2}{|c|}{$\begin{array}{l}\text { Primary } \\
(\mathrm{N}=28)\end{array}$} & \multicolumn{2}{|c|}{$\begin{array}{l}\text { Secondary } \\
(\mathrm{N}=36)\end{array}$} & \multicolumn{2}{|c|}{$\begin{array}{l}\text { Others } \\
(\mathrm{N}=12)\end{array}$} & \multicolumn{2}{|c|}{$\begin{array}{l}\text { University } \\
(\mathrm{N}=44)\end{array}$} & \multirow[t]{2}{*}{$F$} & \multirow[t]{2}{*}{$p$} \\
\hline & $M$ & $S D$ & $M$ & $S D$ & $M$ & $S D$ & $M$ & $S D$ & $M$ & $S D$ & & \\
\hline Identity & 5.40 & 3.50 & 4.57 & 2.17 & 6.19 & 2.52 & 4.50 & 2.47 & 5.45 & 2.35 & 2.119 & 0.082 \\
\hline Timeline & 3.4 & 0.66 & 4.06 & 0.64 & 3.75 & 0.7 & 4.04 & 0.76 & 4.05 & 0.48 & 3.366 & $0.012^{*}$ \\
\hline Consequences & 2.95 & 0.35 & 2.88 & 0.57 & 2.76 & 0.39 & 2.61 & 0.87 & 2.99 & 0.63 & 1.521 & 0.200 \\
\hline Personal control & 3.97 & 0.55 & 4.36 & 0.41 & 4.21 & 0.52 & 4.15 & 0.60 & 4.11 & 0.69 & 1.243 & 0.296 \\
\hline Treatment control & 3.44 & 0.44 & 3.89 & 0.4 & 4.01 & 0.43 & 4.07 & 0.45 & 3.91 & 0.45 & 3.827 & $0.006^{* *}$ \\
\hline Coherence & 3.2 & 0.72 & 3.38 & 0.85 & 3.54 & 0.92 & 3.55 & 1.2 & 3.34 & 0.86 & 0.491 & 0.742 \\
\hline Evolution & 2.7 & 0.59 & 3.0 & 1.15 & 2.88 & 0.91 & 2.73 & 1.22 & 2.74 & 0.73 & 0.444 & 0.776 \\
\hline Emotional representations & 2.62 & 0.52 & 2.65 & 0.76 & 2.7 & 0.83 & 2.24 & 1.03 & 2.5 & 0.77 & 0.936 & 0.445 \\
\hline
\end{tabular}

${ }^{*} p<0.05 ;{ }^{* *} p<0.01$.

versus primary education $(p=0.049, d=1.02)$ and versus university education ( $p=0.036, d=1.25$ ), with participants with higher education scoring higher. In the treatment control dimension, significant or marginally significant differences were found between participants without studies and the remaining participants, such that participants with no education scored lower $(p=0.06, d$ $=1.10 ; p=0.004, d=1.32 ; p=0.009, d=1.41 ; p=$ $0.027, d=1.04$, respectively). We also found a marginally significant difference in identity beliefs between the participants with primary versus secondary education levels, with primary-educated participants indicating fewer symptoms $(p=0.102, d=0.68)$. A moderate effect size was also found for the non-significant difference in identity beliefs between participants who had secondary-level education and those with other formal education $(d=$ 0.67). Although no further significant differences were found, we obtained two other large effect sizes that included the dimension of personal control, in the comparison between participants with no formal education and those with primary studies $(d=0.87)$, and the dimension of timeline, in the comparison between participants without studies and those with other formal studies $(d=0.89)$.

\subsection{Influence of Family Experience with the Disease on Hypertension Representations}

When we compared the representations of hypertension of participants who had never lived with a person with hypertension and those who were currently living with someone with this disease or who had done so in the past, we generally found that those who had experience with the disease had stronger beliefs on all dimensions except consequences and emotional representations. Significant differences were found for the dimensions of personal control, treatment control, evolution and emotional representations (see Table 6). Effect sizes were up to moderate for these differences.

\subsection{Predictors of the IIIness Perceptions on Hypertension}

Finally, to establish which variable(s), if any among the sociodemographic and family experience variables, significantly predicted hypertension representations, we conducted a step-wise multiple regression analysis. We considered the outcome variable to be the total IPQ-R score obtained by adding all the partial scores (except for the causes dimension) such that the higher the global score, the more robust the beliefs about hypertension. Controlling for age, gender and educational level (none of which explained an independent, significant proportion of the predicted variable in an analysis conducted as a first step), family experience was the only significant predictor, explaining $3.2 \%$ of the IPQ-R total score (corrected $R^{2}=0.032 ; F=5.307, p=0.023$ ). Having a relative diagnosed with the disease increased a person's score by 0.2 units (standardised beta $=-0.200 ; t=$ $-2.304, p=0.023$ ). Although the influence of family experience is small, it is a significant impact.

\section{DISCUSSION}

Although the SRM has been applied to different physiccal and mental illnesses, there are relatively few studies regarding the non-specialised beliefs that healthy people hold and how their beliefs influence health- and diseaserelated behaviours [e.g., 16,21,27,41,45,46]. This is particularly true for the Spanish population. Furthermore, research specific to hypertension is scarce, although this disease is one of the leading causes of morbidity in the world and one of the main risks factors for serious pathologies such as heart attack, stroke or chronic renal failure. Consequently, healthy people, risk populations, patients, relatives of patients and even health professionals are in need of tailored interventions. This study focused on establishing the representations of hypertension among healthy, normotensive Spanish adults of both genders and with diverse educational backgrounds and vary- 
Table 6. Comparisons according to experience with the disease.

\begin{tabular}{|c|c|c|c|c|c|c|c|}
\hline \multirow[t]{2}{*}{ DIMENSIONS } & \multicolumn{2}{|c|}{$\begin{array}{l}\text { EXPER. } \\
(\mathrm{N}=50)\end{array}$} & \multicolumn{2}{|c|}{$\begin{array}{l}\text { NO EXPER. } \\
\quad(\mathrm{N}=80)\end{array}$} & \multirow[t]{2}{*}{$t$} & \multirow{2}{*}{$p$} & \multirow[t]{2}{*}{$d$} \\
\hline & $M$ & $S D$ & $M$ & $S D$ & & & \\
\hline Identity & 5.66 & 2.58 & 5.20 & 2.47 & 1.016 & 0.312 & -0.18 \\
\hline Timeline & 3.99 & 0.69 & 3.87 & 0.62 & 0.974 & 0.332 & -0.19 \\
\hline Consequences & 2.8 & 0.56 & 2.9 & 0.58 & -0.975 & 0.331 & 0.17 \\
\hline Treatment control & 4.06 & 0.41 & 3.82 & 0.45 & 3.040 & $0.003^{* *}$ & -0.55 \\
\hline Coherence & 3.57 & 0.89 & 3.32 & 0.88 & 1.580 & 0.117 & -0.28 \\
\hline Evolution & 3.15 & 0.93 & 2.63 & 0.85 & 3.232 & $0.002^{* *}$ & -0.59 \\
\hline Emotional representations & 2.35 & 0.79 & 2.71 & 0.77 & -2.562 & $0.012^{*}$ & 0.46 \\
\hline
\end{tabular}

Equal variances assumed for all. ${ }^{*} p<0.05 ;{ }^{* *} p<0.01$.

ing family experience with the disease. In summary, we found that the participants' beliefs about hypertension were fairly accurate but also deviated from medical knowledge in some respects. Our findings also indicated that there was a little influence of educational level gender and age. However, a personal experience of having lived with a hypertensive patient had a relevant impact on the contents of illness representations.

Descriptive findings indicated that hypertension was considered by non-patients to be a symptomatic, stable and durable (i.e., chronic) disease that is highly controllable by both the patient and by treatments and that has only a moderate impact on the patient's life. Specifically, the participants believed that the patients experience an average of five symptoms related to high blood pressure, such as fatigue or tiredness, tachycardia, dizziness or vertigo (identified by 3 out of 4 participants), and even pain or mood disturbances (identified by almost half of participants). These data stand in contrast to the asymptomatic character of hypertension, the so-called "silent killer", at least until the disease becomes very advanced. The results are consistent with others' findings obtained from patients $[37,39,41]$ and indicate the necessity for non-specialised people of looking for indicators of the presence of the illness (signs and symptoms) as a way to identify when they are ill or not.

For the majority of the participants, hypertension was seen as a moderately severe, life-long disease that causes some difficulties to patients but not to their families. This perception may derive from the severe pathologies that follow from hypertension and not to hypertension itself, which generally does not have a significant impact on patients' daily lives. Furthermore, hypertension was perceived as a disease whose development, evolution and recovery are controllable by both the patient and the available treatments. Participants implicated behavioural and psychological factors, such as eating habits, stress and substance abuse (e.g., smoking, alcohol intake) more frequently. Uncontrollable causes, such as age or genet- ics, were also indicated. This finding may be due to the way hypertension is treated in prevention interventions, where management of controllable psychosocial aspects is emphasised to decrease the impact of other uncontrollable risk factors. Moreover, a very high percentage of the sample believed that available treatments could bring relief from symptoms of the illness; however, hypertension was not perceived as a curable disease.

Regarding its course and evolution, hypertension was perceived as a stable disease, although one out of three people believed that it goes through cycles in which the symptoms increase or decrease. Half of participants affirmed they had poor understanding of the disease. This low level of understanding probably is related to the asymptomatic nature of hypertension and the absence of clear signs of the disease beyond blood pressure tests, at least in the initial disease stages. These circumstances can impede the layperson's grasp of the disease and its characteristics, although the high incidence and prevalence of hypertension is a reality of our culture.

Regarding the emotional representations, we found that participants did not feel particularly worried, fearful or sad when thinking about developing this disease. This low perceived emotional impact stands in contrast with the fact that almost 6 out of 10 participants considered hypertension a serious illness and almost half of them believed that it has important consequences for patients. Although hypertension has a high incidence and prevalence in the population worldwide and it can be associated with serious or even lethal disorders, this is perceived as only occurring in a relatively low proportion of hypertensive patients. Hence, the vast majority felt that suffering from this illness does not mean experiencing very serious consequences in daily life or general health.

Our results support previous findings regarding both the content and fit of beliefs on hypertension with objective medical knowledge [37-39] and are similar in many respects to those obtained in a Spanish study [23]. In our study, hypertension representations were generally accu- 
rate but sometimes they differed from medical knowledge and were based on common sense, cultural beliefs and folk knowledge. Other researchers have stated that laypeople's illness cognitions of diverse physical illness diverge sharply from current medical understanding [14, $21,23,37,39,41,47,48]$.

Research exploring the influence of sociodemographic factors on lay representations of hypertension is scarce. Contrary to findings by Ross et al. (2004), we have found that sociodemographic variables have little influence on hypertension cognitions. When we examined the impact of gender, we only found that, compared to women, men perceived significantly more frequent or severe consequences of hypertension (i.e., men perceived hypertension as more serious, with a strong and broad impact to patients, their relatives and caregivers). With regard to age, only 2 significant differences in 80 comparisons were found. Some significant differences emerged for educational level, although only regarding the disease timeline and treatment control dimensions. The general tendency of the significant findings was, as expected, that a higher level of formal education led to more accurate beliefs.

As we documented in the Introduction, direct experience with an illness, in terms of suffering from the disease or caring for a patient, is proposed by the SRM and has been found to have an important influence on the construction of illness representations. To date these influences from personal experience with the disease have not been broadly explored in the case of hypertension [e.g., 23,41]. In our study, after controlling for sociodemographic variables, personal experience (i.e., living with a patient) was the only significant predictor of hypertension representations. Furthermore, patients' relatives or caregivers perceived hypertension as significantly more manageable by both patients and treatments. People who had lived with a hypertensive patient also perceived the disease as significantly more unpredictable and changeable, with improvements and relapses over time. They also reported a significantly lower level of negative feelings of worry, fear or sadness when faced with the possibility of suffering from hypertension themselves. This apparent emotional immunity may be linked to their daily experience with the disease and its consequences.

The SRM proposes that illness-related behaviours, such as adhering to a healthy habit or to drug treatments, are strongly influenced by illness perceptions. Patients and non-patients consider whether such behaviour changes are consistent with what they believe about the illness and its management when deciding on complying with the recommended changes. In the case of hypertension particularly, adherence to behavioural changes has an added importance because inaccurate beliefs about this illness [37-39,41,49], particularly about its causes [42], together with its asymptomatic nature, seem to negatively affect adherence to prescribed treatments and preventive or therapeutic behaviours.

It is important to know how a very extended but preventable disease such as hypertension is understood by healthy laypeople and to know which beliefs derive from a direct experience with the disease so that interventions, such as health promotion and disease prevention programmes, can be targeted appropriately. Our findings provide a basis for new research and interventions aimed at hypertension prevention. As the SRM suggests, patients cope with their disease and its impact based on their beliefs and, for example, adhere to treatments, selfregulate emotional distress or adopt self-care activities or changes in lifestyles if they believe something can be done to manage the disease, its symptoms and its consequences for their lives. Similarly, it is expected that healthy people avoid risks, seek medical care, undergo medical exams and adopt new healthy behaviours if they believe they can act to prevent a disease. In our study, 3 out of 4 participants perceived hypertension as a preventable disease. Previous research has established a positive relationship between perceptions about an illness and the attitudes, intentions and actions regarding future protective and preventive behaviours [26,50-52]. Thus, it is expected that more accurate beliefs will lead non-patients to carry out more appropriate and beneficial actions to face illnesses before a diagnosis is given. Individually focused revision and discussion of illness beliefs should modify misconceptions and biased, inappropriate and unrealistic expectations.

Understanding the illness beliefs held by healthy people would also provide insights as to how a particular illness or health-threatening condition is perceived prior to a possible personal or family experience with the disease. It would help us to understand how these representations are changed by the illness experience; how they relate to specific coping behaviours, adjustment and health outcomes with and without personal or family experience; and how this information can be used to derive preventive and therapeutic interventions aimed at modifying illness beliefs in both patients and non-patients. Furthermore, such knowledge would allow us to inform appropriate preventive and therapeutic interventions, so as the emotional and behavioural managing actions of nonpatients and patients could be better adjusted to their respective conditions and result in more positive outcomes in terms of health and well-being and management of risks. Our study also stresses the key role of health psychologists in primary and specialised care and, more broadly in community health policies and campaigns, for educating both laypeople (patients, non-patients, relatives and caregivers) and specialised staff. 
However, some limitations of this study should be considered in future research. Given the scarcity of studies on hypertension representations in Spanish samples we encourage researchers to conduct new studies aimed at replicating our results and to include cross-cultural comparison purposes. It would be advisable to increase the number of participants and to include a more heterogeneous sample. Further, sample size made comparisons between groups to have been done with small groups, limiting the statistical power of the analyses. The reliance on self-reported diagnoses of personal and family member hypertension has important limitations, as prevalence may be under- or overestimated. Nonetheless, this procedure has been found to show a moderate to excellent agreement with epidemiological, population-based prevalence in nationwide samples [53-55]. Thus, selfreports are considered valid and an appropriate indicator for the surveillance of hypertension prevalence in the absence of blood pressure measurement. Researchers and health specialists are increasingly obtaining information on chronic illnesses from self-reports [e.g., 56-60]. Future research should also compare the beliefs of nonpatients, caregivers, patients with hypertension and people who have suffered from hypertension. Further, neither the type and accuracy of knowledge the participants had nor the sources of said knowledge were considered herein, and it would be appropriate to know and compare the beliefs of people who have significant medical knowledge with those held by people with no specialised knowledge. It would be also interesting to consider participant's current or future risk of having hypertension due to behavioural or genetic causes. Finally, it would be interesting to explore how illness perceptions themselves change over time in response to new influences, such as an individual's personal and/or family experience with the illness.

\section{ACKNOWLEDGEMENTS}

This research was partially supported with the financial aid provided to the "Medicina Conductual/Psicología de la Salud" Research Group (CTS-0267) by the Consejería de Innovación, Ciencia y Empresa, Junta de Andalucía (Spain). We are grateful to all the participants and assistants who made this study possible.

\section{REFERENCES}

[1] Hajjar, I., Morley Kotchen, J. and Kotchen, T.A. (2006) Hypertension: Trends in prevalence, incidence, and control. Annual Review of Public Health, 27, 465-490. doi:10.1146/annurev.publhealth.27.021405.102132

[2] Kearney, P.M., Whelton, M., Reynolds, K., Muntner, P. and Whelton, P.K. (2005) Global burden of hypertension: Analysis of worldwide data. Lancet, 365, 217-222.

[3] Wolf-Maier, K., Cooper, R.S., Banegas, J.R., Giampaoli,
S., Hense, H.W., Joffres, M., Kastarinen, M., Poulter, N., Primatesta, P., Rodriguez Artalejo, F., Stegmayer, B., Tuomilehto, J., Vanuzzo, D. and Vescio, F. (2003) Hypertension prevalence and blood pressure levels in 6 European countries, Canada and the United States. JAMA, 289, 2363-2369. doi:10.1001/jama.289.18.2363

[4] Sociedad Española de Hipertensión-Liga Española para la Lucha contra la Hipertensión Arterial (2005) Guía española de hipertensión arterial. Hipertensión, 22, S2.

[5] Diefenbach, M.A. and Leventhal, H. (1996) The common-sense model of illness representations: Theoretical and practical considerations. Journal of Social Distress and the Homeless, 5, 11-38. doi:10.1007/BF02090456

[6] Leventhal, H. and Diefenbach, M. (1991) The active side of illness cognition. In: Skelton, R.T. and Croyle, M., Eds., Mental Representation in Health and Illness, Springer Verlag, New York, 247-272.

doi:10.1007/978-1-4613-9074-9_11

[7] Leventhal, H., Meyer, D. and Nerenz, D. (1980) The common sense model of illness danger. In: Rachman, S., Ed., Medical Psychology, Vol. 2, Pergamon, New York, 7-30.

[8] Leventhal, H., Nerenz, D.R. and Steele, D.F. (1984) Illness representations and coping with health threats. In: Baum, A., Taylor, S.E. and Singer, J.E., Eds., A Handbook of Psychology and Health: Sociopsychological Aspects of Health, Erlbaum, Hillsdale, 219-252.

[9] Leventhal, H., Diefenbach, M. and Leventhal, E.A. (1992) Illness cognition: Using common sense to understand treatment adherence and affect cognition interactions. Cognitive Therapy and Research, 116, 143-163. doi:10.1007/BF01173486

[10] Leventhal, H., Benyamini, Y., Brownlee, S., Diefenbach, M., Leventhal, E.A., Patrick-Miller, L. and Robitaille, C. (1997) Illness representations: Theoretical foundations. In: Petrie, K.J. and Weinman, J., Eds., Perceptions of Health and Illness, Harwood Academic, London, 19-47.

[11] Leventhal, H., Leventhal, E. and Contrada, R.J. (1998) Self-regulation, health and behavior. A perceptual cognitive approach. Psychology \& Health, 13, 717-734. doi:10.1080/08870449808407425

[12] Leventhal, H., Leventhal, E.A. and Cameron, L. (2001) Representations, procedures, and affect in illness selfregulation: A perceptual-cognitive model. In: Baum, A., Revenson, T.A. and Singer, J.E., Eds., Handbook of Health Psychology, Lawrence Erlbaum, Mahwah, 19-48.

[13] Leventhal, H., Brissette, I. and Leventhal, E.A. (2003) The common-sense model of regulation of health and illness. In: Cameron, L.D. and Leventhal, H., Eds., The Self-Regulation of Health and Illness Behaviour, Routledge, London, 42-65.

[14] Anagnostopoulos, F. and Spanea, E. (2005) Assessing illness representations of breast cancer: Comparison of patients with healthy and benign controls. Journal of Psychosomatic Research, 58, 327-334. doi:10.1016/j.jpsychores.2004.09.011

[15] Heijmans, M., de Ridder, D. and Bensing, J. (1999) Dissimilarity in patients' and spouses' representations of chronic illness: Exploration of relations to patient adapta- 
tion. Psychology \& Health, 14, 451-466. doi:10.1080/08870449908407340

[16] Lau-Walker, M. (2004) Relationship between illness representation and self-efficacy. Journal of Advanced Nursing, 48, 216-225. doi:10.1111/j.1365-2648.2004.03190.x

[17] Heijmans, M. and de Ridder, D. (1998) Structure and determinants of illness representations in chronic disease: A comparison of Addison's disease and chronic fatigue syndrome. Journal of Health Psychology, 3, 523-537. doi:10.1177/135910539800300406

[18] Lehto, R.H. (2007) Causal attributions in individuals with suspected lung cancer: Relationships to illness coherence and emotional responses. Journal of the American Psychiatric Nurses Association, 13, 109-115. doi:10.1177/1078390307303112

[19] Sterba, K.R. and DeVellis, R.F. (2009) Developing a spouse version of the illness perception questionnaire- revised (IPQ-R) for husbands of women with rheumatoid arthritis. Psychology \& Health, 24, 473-487. doi:10.1080/08870440701867788

[20] Buick, D. and Petrie, K.J. (2002) "I know just how you feel": The validity of healthy women's perceptions of breast cancer patients receiving treatment. Journal of Applied Social Psychology, 32, 110-123. doi:10.1111/j.1559-1816.2002.tb01422.x

[21] Del Castillo, A., Godoy-Izquierdo, D., Vazquez, M.L. and Godoy, J.F. (2011) Illness beliefs about cancer among healthy adults who have and have not lived with cancer patients. International Journal of Behavioral Medicine, 18, 342-351. doi:10.1007/s12529-010-9141-6

[22] Figueiras, M. and Weinman, J. (2003) Do similar patient and spouse perceptions of myocardial infarction predict recovery? Psychology and Health, 18, 201-216. doi:10.1080/0887044021000057266

[23] Godoy-Izquierdo, D., López-Chicheri, I., López-Torrecillas, F., Vélez, M. and Godoy, J.F. (2007) Contents of lay illness models dimensions for physical and mental diseases and implications for health professionals. Patient Education and Counselling, 67, 196-213. doi:10.1016/j.pec.2007.03.016

[24] Lykins, E.L., Graue, L.O., Brechting, E.H., Roach, A.R., Gochett, C.G. and Andrykowski, M.A. (2008) Beliefs about cancer causation and prevention as a function of personal and family history of cancer: A national, population-based study. Psycho-Oncology, 17, 967-974. doi:10.1002/pon.1306

[25] Moss-Morris, R. and Chalder, T. (2003) Illness perceptions and levels of disability in patients with chronic fatigue syndrome and rheumatoid arthritis. Journal of Psychosomatic Research, 55, 305-308. doi:10.1016/S0022-3999(03)00013-8

[26] Sullivan, H.W., Finney Rutten, L.J., Hesse, B.W., Moder, R.P., Rothman, A.J. and McCaul, K.D. (2010) Lay representations of cancer prevention and early detection: Associations with prevention behaviours. Preventing Chronic Disease, 7, 1-11.

[27] Weinman, J., Petrie, K., Sharpe, N. and Walker, S. (2000) Causal attributions in patients and spouses following first-time myocardiac infarction and subsequent lifestyle changes. British Journal of Health Psychology, 5, 263273. doi:10.1348/135910700168900

[28] Weinman, J., Heijmans, M. and Figueiras, M. (2003) Carer perceptions of chronic illness. In: Cameron, L.D. and Leventhal, H., Eds., The Self-Regulation of Health and Illness Behaviour, Routledge, London, 207-219.

[29] Hagger, M.S. and Orbell, S. (2003) A meta-analytic review of the common-sense model of illness representations. Psychology \& Health, 18, 141-184. doi: $10.1080 / 088704403100081321$

[30] Lobban, F., Barrowclough, C. and Jones, S. (2003) A review of the role of illness models in severe mental illness. Clinical Psychology Review, 23, 171-196. doi:10.1016/S0272-7358(02)00230-1

[31] Kaptein, A.A., Scharloo, M., Helder, D.I., Kleijn, W.C., van Korlaar, I.M. and Woertman, M. (2003) Representations of chronic illness. In: Cameron, L.D. and Leventhal, H., Eds., The Self-Regulation of Health and Illness Behaviour, Routledge, London, 97-118.

[32] Petrie, K.J. and Weinman, J. (1997) Perceptions of health and illness. Harwood Academic, London.

[33] Figueiras, M., Marcelino, D.L., Claudino, A., Cortes, M.A., Maroco, J. and Weinman, J. (2010) Patients' illness schemata of hypertension: The role of beliefs for the choice of treatment. Psychology \& Health, 25, 507-517. doi:10.1080/08870440802578961

[34] Fongwa, M.N., Evangelista, L.S., Hays, R.D., Martins, D.S., Elashoff, D., Cowan, M.J. and Morisky, D.E. (2008) Adherence treatment factors in hypertensive African American woman. Vascular Health and Risk Management, 4, 157-166. doi:10.2147/vhrm.2008.04.01.157

[35] Frosch, D.L., Kimmel, S. and Volpp, K. (2008) What role do lay beliefs about hypertension etiology play in perceptions of medication effectiveness? Health Psychology, 27, 320-326. doi:10.1037/0278-6133.27.3.320

[36] Heckler, E., Lambert, J., Leventhal, E., Leventhal, H., Janh, E. and Contrada, R. (2008) Commonsense illness belief, adherence behaviors and hypertension control among African Americans. Journal of Behavioral Medicine, 31, 391-400. doi:10.1007/s10865-008-9165-4

[37] Meyer, D., Leventhal, H. and Gutmann, M. (1985) Common sense models of illness: The example of hypertension. Health Psychology, 4, 115-135. doi:10.1037/0278-6133.4.2.115

[38] Ross, S., Walker, A. and McLeod, M.J. (2004) Patient compliance in hypertension: Role of illness perceptions and treatment beliefs. Journal of Human Hypertension, 18, 607-613. doi:10.1038/sj.jhh.1001721

[39] Schlomann, P. and Schmitke, J. (2007) Lay beliefs about hypertension: An interpretative synthesis of the qualitative research. American Academy of Nurse Practitioners, 19, 358-363. doi:10.1111/j.1745-7599.2007.00238.x

[40] Theunissen, N.C., de Ridder, D.T., Bensing, J.M. and Rutten, G.E. (2003) Manipulation of patient-provider interaction: Discussing illness representations or actions plans concerning adherence. Patient Education and Counseling, 51, 247-258. doi:10.1016/S0738-3991(02)00224-0

[41] Wilson, R.P., Freeman, A., Kazda, M.J., Andrews, T.C., 
Berry, L., Vaeth, P.A. and Victor, R.G. (2002) Lay beliefs about high blood pressure in a low- to middle-income urban African-American community: An opportunity for improving hypertension control. The American Journal of Medicine, 112, 26-30.

doi:10.1016/S0002-9343(01)01049-X

[42] Moss-Morris, R., Weinman, J., Petrie, K., Horne, R., Cameron, L. and Buick, D. (2002) The revised illness perception questionnaire (IPQ-R). Psychology \& Health, 17, 1-16. doi:10.1080/08870440290001494

[43] Weinman, J., Petrie, K., Moss-Morris, R. and Horne, R. (1996) The Illness Perception Questionnaire: A new method for assessing the cognitive representation of illness. Psychology \& Health, 11, 431-435. doi: $10.1080 / 08870449608400270$

[44] Beléndez, R., Bermejo, R.M. and García-Ayala, M.D. (2005) Estructura factorial de la versión española del revised illness perception questionnaire en una muestra de hipertensos. Psicothema, 17, 318-324.

[45] Karademas, E.C., Zarogiannos, A. and Karamvakalis, N. (2010) Cardiac patient-spouse dissimilarities in illness perception: Associations with patient self-rated health and coping strategies. Psychology and Health, 25, 451-463. doi:10.1080/08870440802652089

[46] Kaptein, A.A., Scharloo, M., Helder, D.I., Snoei, I., van Kempen, G.M., Weinman, J., van Houwelingen, J.C. and Roos, R.A. (2007) Quality of life in couples living with Huntington's disease: The role of patients' and partners' illness perceptions. Quality of Life Research, 16, 793-801. doi:10.1007/s11136-007-9194-4

[47] Karasz, A., McKee, M.D. and Roybal, K. (2003) Women's experiences of abnormal cervical cytology: Illness representations, care processes, and outcomes. Annals of Family Medicine, 1, 196-202. doi:10.1370/afm.31

[48] Rees, G., Fry, A., Cull, A. and Sutton, S. (2004) Illness perceptions and distress in women at increased risk of breast cancer. Psychology and Health, 19, 749-765. doi:10.1080/08870440412331279764

[49] Kagee, A., Le Roux, M. and Dick, J. (2007) Treatment adherence among primary care patients in a historically disadvantaged community in South Africa. Journal of Health Psychology, 12, 444-460. doi:10.1177/1359105307076232

[50] Cameron, L.D. (2008) Illness risk representations and motivations to engage in protective behavior: The case of skin cancer risk. Psychology \& Health, 23, 91-112. doi:10.1080/14768320701342383

[51] Claassen, L., Henneman, L., Kindt, I., Marteau, T.M. and Timmermans, D. (2010) Perceived risk and representa- tions of cardiovascular disease and preventive behaviour in people diagnosed with familial hypercholesterolemia: A cross-sectional questionnaire study. Journal of Health Psychology, 15, 33-43. doi:10.1177/1359105309345170

[52] Figueiras, M.J. and Alves, N.C. (2007) Lay perceptions of serious illnesses: An adapted version of the revised illness perception questionnaire (IPQ-R) for healthy people. Psychology \& Health, 22, 143-158. doi:10.1080/14768320600774462

[53] Selem, S.S., Castro, M.A., Galvao, C.L., Lobo, D.M. and Fisberg, R.M. (2012) Validity of self-reported hypertension is inversely associated with the level of education in Brazilian individuals. Arquivos Brasileiros de Cardiologia, 100, 52-59.

[54] Van Eenwyk, J., Bensley, L., Ossiander, E.M. and Krueger, K. (2012) Comparison of examination-based and self-reported risk factors for cardiovascular disease, Washington State, 2006-2007. Prevention of Chronic Disease, 9, 321-332.

[55] Lima-Costa, M.F., Peixoto, S.V. and Firmo, J.O. (2004) Validity of self-reported hypertension and its determinants (the Bambuí study). Revista de Saúde Pública, 38, 637-642. doi:10.1590/S0034-89102004000500004

[56] Estoppey, D., Paccaud, F., Vollenweider, P. and MarquesVidal, P. (2011) Trends in self-reported prevalence and management of hypertension, hypercholesterolemia and diabetes in Swiss adults, 1997-2007. BMC Public Health, 11, 114-123. doi:10.1186/1471-2458-11-114

[57] Kaplan, M., Huguet, N. and Feeney, D.H. (2010) Selfreported hypertension prevalence and income among older adults in Canada and the United States. Social Science and Medicine, 6, 844-849. doi:10.1016/j.socscimed.2009.11.019

[58] Pereira, M., Carreira, H., Vales, C., Rocha, V., Azevedo, A. and Lunet, N. (2012) Trends in hypertension prevalence (1990-2005) and mean blood pressure (1975-2005) in Portugal: A systematic review. Blood Pressure, 4, 220226. doi: $10.3109 / 08037051.2012 .666380$

[59] Pitsavos, C., Milias, G.A., Panagiotakos, D.B., Xenaki, D., Panagopoulos, G. and Stefanadis, C. (2006) Prevalence of self-reported hypertension and its relation to dietary habits, in adults; a nutrition \& health survey in Greece. BMC Public Health, 6, 206-214. doi:10.1186/1471-2458-6-206

[60] Valderrama, A.L., Tong, X., Ayala, C. and Keenan, N.L. (2008) Prevalence of self-reported hypertension, advice received from health care professionals, and actions taken to reduce blood pressure among US adults health styles. The Journal of Clinical Hypertension, 12, 222-232. 